\title{
Development of the Supply Chain Oriented Quality Assurance System for Aerospace Manufacturing SMEs and Its Implementation Perspectives
}

\author{
HUSSEIN Abdullahi and CHENG Kai* \\ College of Engineering, Design and Physical Sciences, Brunel University London, Uxbridge UB8 3PH, UK
}

Received May 24, 2016; revised August 31, 2016; accepted September 7, 2016

\begin{abstract}
Aerospace manufacturing SMEs are continuously facing the challenge on managing their supply chain and complying with the aerospace manufacturing quality standard requirement due to their lack of resources and the nature of business. In this paper, the ERP system based approach is presented to quality control and assurance work in light of seamless integration of in-process production data and information internally and therefore managing suppliers more effectively and efficiently. The Aerospace Manufacturing Quality Assurance Standard (BS/EN9100) is one of the most recognised and essential protocols for developing the industry-operated-and-driven quality assurance systems. The research investigates using the ERP based system as an enabler to implement BS/EN9100 quality management system at manufacturing SMEs and the associated implementation and application perspectives. An application case study on a manufacturing SME is presented by using the SAP based implementation, which helps further evaluate and validate the approach and application system development.
\end{abstract}

Keywords: BS/EN 9100 Quality Assurance, aerospace manufacturing, ERP system, aerospace quality assurance, SAP programming

\section{Introduction}

Today's aerospace manufacturing supply chains have become ever more complex due to the global market competition and manufacturing globalization ${ }^{[1]}$, which is often illustrated through the stretched network of suppliers, manufacturers, distributers, warehouses and retailers, etc. The respective performance of these different stakeholders or players involved in the supply chains should be transparent and qualitatively assured, since through them the raw materials are purchased, manufactured, processed and/or services delivered to customers both in upstream and downstream. The global competitive market has led to the aerospace manufacturing OEMs to outsource based on manufacturing capabilities. This has led to more complex organization and a long network chain of suppliers.

The supply chain management (SCM) is the whole process approach to manufacturing sourcing, inventory, purchasing, logistics, and production management, etc ${ }^{[2]}$. The term supply chain is interpreted differently. Some inrepretations are related to management processes, while others stress the structural organization of businesses. However, SCM integrates the management of supply and demand $^{[3]}$. Procurement of goods and services normally represents the largest single category of spending, ranging from $50 \%$ to $80 \%$ of revenues, in most manufacturing

* Corresponding authors: E-mails: kai.cheng@brunel.ac.uk

(c) Chinese Mechanical Engineering Society and Springer-Verlag Berlin Heidelberg 2016 $\operatorname{organizations}^{[4]}$. Therefore, improving quality and productivity through effective supply management practice is critical to manufacturing SMEs. The aerospace manufacturing SCM is considered to be one of the major challenges for the industry. This is due to aerospace manufacturing industry being characterized as more supply chain oriented and a large number of SMEs are participated. Whereas the automotive manufacturing is more tiers based and they are mainly big suppliers on mass production scale. Manufacturing SMEs play a big role in the aerospace industry ${ }^{[5]}$. These SMEs manufacture highly specialized components or outsourced processes. The aerospace industry has evolved a distinctive pyramid supply chain structure from these manufacturing SMEs. The aerospace industry relies heavily on the supply chain, which has a big impact on both quality and delivery performance. The equipment sector accounts for $34 \%$ of those employed in the industry. However,this figure is deceptive in that although it includeslarger suppliers like Smiths and Cobham, it excludes many small suppliers that are not classifiedas aerospace companies, because they also supply other sectors, such as the automotive industry. These small suppliers produce specialized components or function as sub contractors. It is estimated that small and mediumsized enterprises constitute, 'the bulk of the industry in terms of revenue and employment ${ }^{[6]}$. It is the large number of small equipment suppliersthat helps to give the aerospace industry its distinctive pyramid structure ${ }^{[5]}$, made up of some 3000 companies in total.

BS/EN9100 is the quality system standard for the 
aerospace industry, which has been recognized throughout the industry internationally. BS/EN9100 is a broadly recognised and standardized quality management system for the aerospace industry and major aerospace manufacturers are BS/EN9100 certified, including Boeing, Airbus, Messier-Dowty and Rolls-Royce ${ }^{[7]}$. The current revision of the standard - BS/EN9100 Rev C is based on ISO 9001:2008 and was released in 2009. The new BS/EN9100 Rev D is expected to be released in April 2016 and there will be a three year transition period for companies to comply with the new revision ${ }^{[8]}$. There are a significant number of engineering SMEs pursuing the certification BS/EN9100 aerospace quality management system standard ${ }^{[9]}$. The certification of BS/EN9100 is not only a prerequisite for engineering SMEs to gain entrance to the aerospace manufacturing supply chain, but it is also imposed on the first tier suppliers to OEMs. BS/EN9100 is a quality standard that introduces world class engineering practices for SMEs to standardize their way to work within the industry. Furthermore, it assists firms to meet regulatory, statutory and customer requirements so as to become more reliable and stronger competitors in providing products and services to the highest aerospace manufacturing standard.

The BS/EN9100 quality standard reflects the nature of the industry and puts great importance on supply chain management ${ }^{[10]}$. The standard includes additional clauses and more stringent requirements for identifying and maintaining suppliers. The certification body audits the purchasing and supply chain management process on every surveillance audit being conducted at the clients premises $^{[11]}$. Most of the manufacturing SMEs work for different industries other than the aerospace. This makes it challenging for these SMEs to maintain quality assurance requirement for different industries, of which the aerospace is the most demanding one. The resources are also limited for most SMEs to comply with these requirements particularly in maintaining and monitoring suppliers. There is no functional Supplier Quality Assurance department or purchasing department at most manufacturing SMEs.

In the past, the quality management system and its implementation were mainly based on document driven approach and the associated procedures and activities. With the advance of current economic and technological development, it is tedious, inefficient and no longer sustainable to use such approach. The ERP system is playing an increasingly important role in supply chain management processes. It also helps aerospace manufacturing SMEs manage many business and production aspects within the company such as inventory management, finance and production process planning, etc. It can be used to provide the real-time access to business information. All supply chain management activities are likely supported by using the same system, including the suppliers register, delivery performance monitoring, purchase orders, and financial transactions, etc. Traceability is an important requirement in BS/EN9100 quality assurance. To address the challenge and achieve the entire SCM process traceability goals, manufacturers need to have a robust global manufacturing traceability solution. ERP based systems can provide the capability for the supply network traceability, and maintain links between end products and the raw materials, components, labor, processes, machines, and time invested in manufacturing them respectively, and further render the ability to trace products based on their manufacturing inputs as well as to keep all the associated documents and records in real time ${ }^{[12]}$. Existing basic IT technologies and systems need to be adapted to the industry'sparticular requirements of manufacturing and continue to be developed ${ }^{[13]}$. The key benefit of a dopted technologiesto SMEs is the ability to combine the strengths of the manufacturers and suppliers to meet a certain market need ${ }^{[14]}$. This also makes suppliers gain a competitive advantage. SCM competitiveness can be seen as a comparativeconcept of the ability and performance of a supply paradigm torespond to a demand paradigm $^{[15]}$.

The approach presented in this paper is concerned with how to reconfigure and customize the ERP system in order to reflect the requirements of BS/EN9100 Rev C for supply chain management and quality assurance. This is undertaken and illustrated through the application case study on using the SAP modules and integrating them with the aerospace quality control and assurance clauses. This paper is organized as follows; i.e., it firstly presents the development of suppliers selection protocols based on the BS/EN9100 standard, and then the development of the supplier selection KPIs (Key Performance Indicators) algorithms. A case study on an aerospace manufacturing firm is further presented, covering the SAP based system configuration, supplier management, in-process supplier management and decision makings, and implementation perspectives of using the SAP based system.

\section{Development of Suppliers Selection Protocols and Algorithms Based on the BS/EN9100}

The standard specifies requirements for the purchasing process as described in BS/EN9100 clause 7.4.1, which can be further developed as the selection protocol and the associated algorithm as illustrated in Fig. 1. A procedure was established to define the requirements as follows:

(1) Maintaining a register of its suppliers, this includes approval status and the scope of the approval for each supplier.

(2) Periodical review of the supplier's performance.

(3) Defining the necessary actions to take in dealing with suppliers who are poorly performed.

(4) Ensuring where required that both the company case studied (Mollart Engineering Ltd) and all suppliersuse the customer-approved special process sources. 
(5) Defining the process, responsibilities and authority for the approval status decision, changes of the approval status and conditions for a controlled use of suppliers.

(6) Determining and managing the risks in selecting and using suppliers.

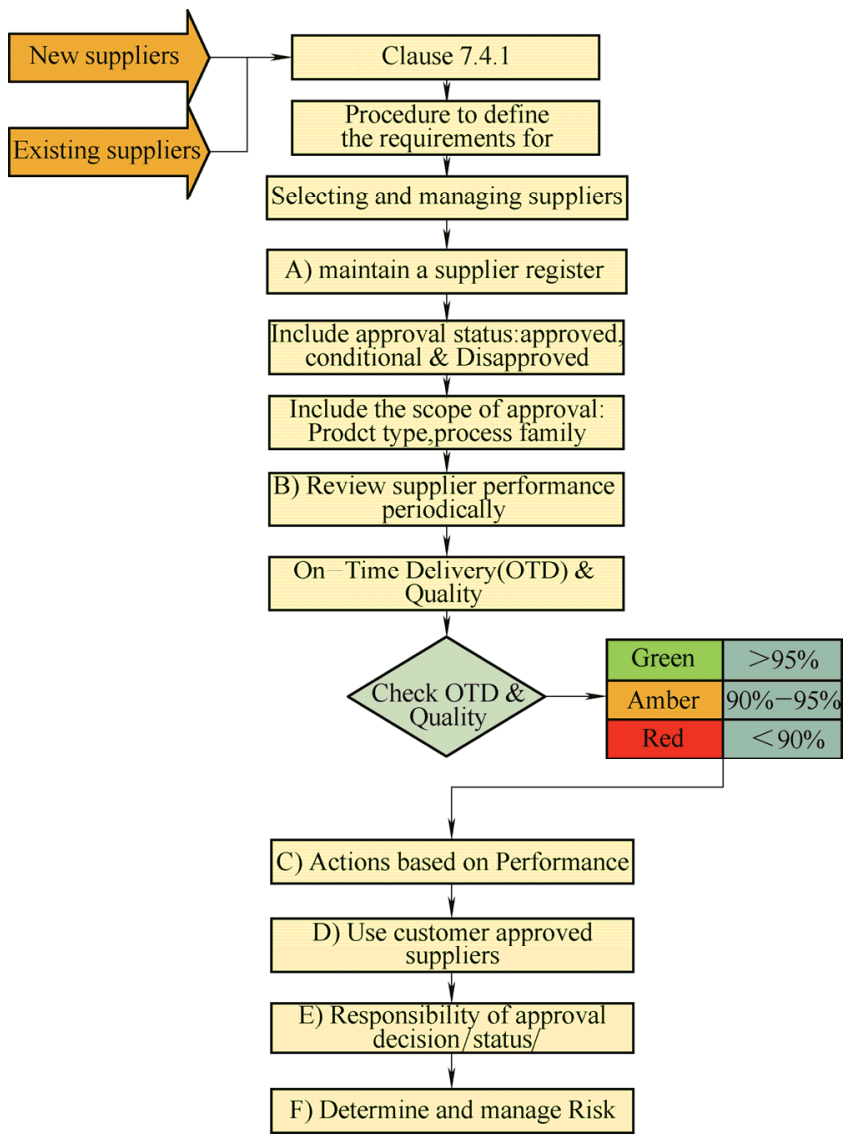

Fig. 1. Protocol and the associated algorithm for selecting and managing new suppliers further developed from BS/EN9100 clause 7.4.1

The algorithms are developed based on the above requirements of the standard related to supply chain management and the purchasing process. After that, the algorithms can be implemented within the computer aided engineering environment, e.g., ERP or PDM, following the correct steps accordingly. The clauses of the BS/EN9100 aerospace standard related to supply chain management and purchasing include BS/EN9100 clauses 7.4, 7.4.3, 7.5.3, 7.5 .4 and $7.5 .5^{[16]}$. For instance, the standard clause $7.4 .1 \mathrm{~b}$ states that the supplier's performance to be periodically reviewed $^{[16]}$. The performance specified by the standard is according to the suppliers KPIs. The KPIs related to supply chain management are the supplier's on-time delivery and quality performance.

The ERP system can be built in with the KPI algorithms as illustrated in Fig. 2, which can then enable the up-to-the-minute visibility to KPIs across every facet of business operations. It includes enabling real-time monitoring, root cause analysis, risk mitigation, predictive modeling, and optimization, etc., which can thus help the manufacturing company run the more intelligent aerospace manufacturing with the quality control and assurance in a predictive manner as indicated in Fig. 3. However, the figure only illustrates a small instant part of the interactive dynamic process at the system operations. The formulation illustrated in Fig. 3 provides the analytics for quantitative dynamic analysis on the suppliers' delivery and quality performance. The dashboard system with green, amber and red lights is used to identify and indicate the performance of a particular supplier based on the percentage acceptance category, while corresponding actions can be taken based on the percentage performance accordingly in process.

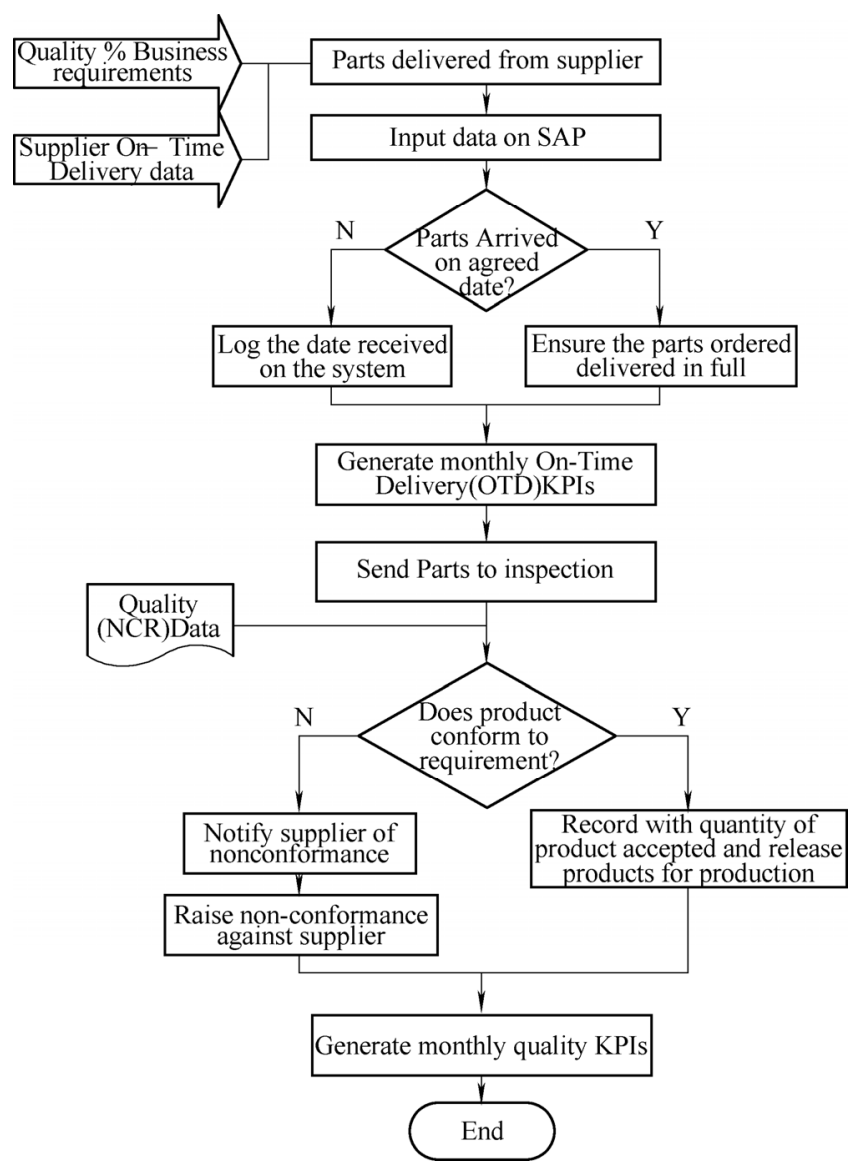

Fig. 2. Supplier performance monitoring algorithm developed on the basis of clause 7.4.1b

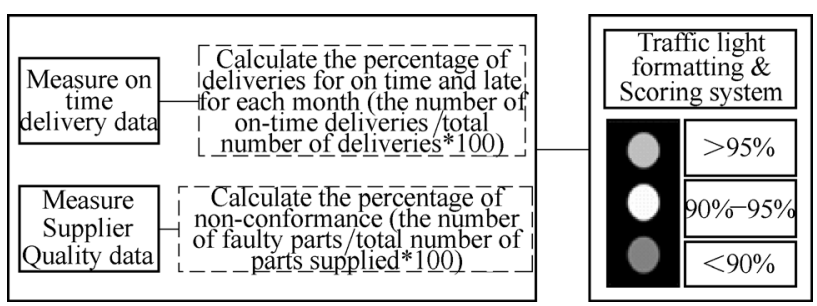

Fig. 3. Supplier performance scoring dynamically illustrated during the system operations

\section{Case Study on An Aerospace Manufacturing SME}

A case study on an aerospace manufacturing SME firm was used to carry out the investigation of implementing the 
BS/EN9100 aerospace quality standard. The firm is a precision engineering firm currently undertaking both the implementation of a new ERP system as well as the aerospace manufacturing standards. The investigation was related to the requirements of the aerospace quality standard for purchasing and supply chain management. The SAP based ERP system was used as a key engineering tool to enable the firm to meet the engineering requirement.

Part of the requirements of the standard is that every supplier affecting the final product has to be approved. Manufacturing firms generally use a large supply base varying from the domestic supply to raw materials procurement. This would be a huge exercise if going through every single supplier, since the number of suppliers for this firm is around 1600 on the system. The stages being gone through to manage the suppliers on the system are as follows.

(1) System configuration to meet the requirements.

(2) Identifying suppliers with no transactions made for more than 12 months and making them disapproved and inactive on the system.

(3) Sending every supplier a quality questionnaire and the Supplier Quality Assurance requirement document stating some of the additional requirements of BS/EN9100.

(4) Suppliers performance KPIs development.

(5) In-process management and decision makings.

(6) Analysis on the performance of suppliers and taking acts accordingly.

The supplier quality assurance requirement document addresses some of the requirements in clause 7.4.2 as well as the organization specific requirements ${ }^{[16]}$. Some of the requirements included in the document are as follows.

(1) The supplier to:

1) Notify the organisation of nonconforming product;

2) Obtain the approval for nonconforming product disposition;

3) Notify the organisation of changes in the product and/or process, changes of suppliers, and changes of manufacturing facility locations;

4) Flow down to the supply chain the applicable requirements;

5) Alarm and inform the organisation if the quality certification is withdrawn.

(2) Record retention requirements.

(3) Right to access by the organisation, their customer and regulatory authorities to the applicable areas of all facilities at any level of the supply chain, involved in the order and all applicable records during the course of the contract.

(4) Contract/Purchase order requirement as a legal document.

(5) Certificate of the conformance.

(6) Traceability requirements.

(7) Packaging requirements and delivery documentation.

(8) Inspection/test requirements (maintaining measurement equipment and inspection records, etc).
(9) Supplier performance and auditing.

\subsection{System configuration}

In the suppliers section, additional fields were added to meet the standard requirements as shown in Fig. 4. These include the approval status, scope of the approval, any restrictions, what quality certification they have, expiry date for the third party certification body and whether they are a customer approved supplier or approved by the organization, etc. These additional fields added are essential to comply with the BS/EN9100 requirements on purchasing

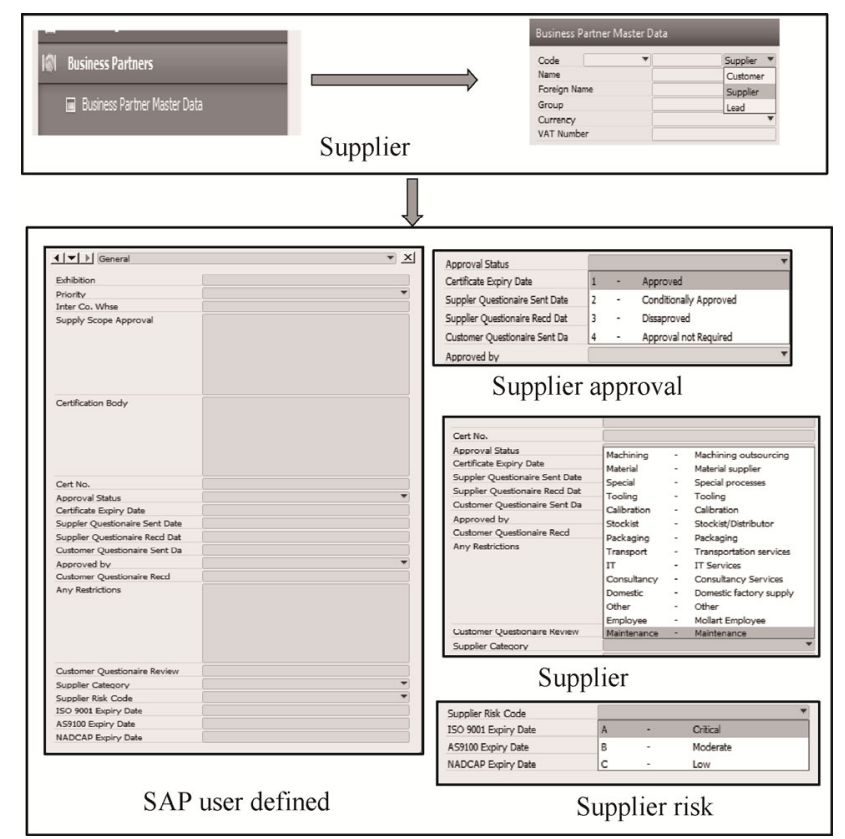

Fig. 4. SAP system reconfigured and customized by the user defined fields

\subsection{Suppliers management}

The standard in BS/EN9100 clause 7.4.1a requires organizations to maintain the register for approved suppliers ${ }^{[16]}$. This can be managed by using the SAP based ERP system. BS/EN9100 requires manufacturing companies to have an approved supplier register, which means the purchasing can only be carried out from the suppliers approved based on approval criteria. The SAP based system can provide the access to only the quality manager to change the approval status of suppliers. It will also restrict buyers from purchasing from the unapproved suppliers.

New supplier Selection \& Approval process is just one step in the process of managing suppliers. The most important element of this part of the standard is the understanding that a supplier is responsible for managing its own suppliers and sub-tier suppliers. The standard requirement is that organization shall establish a new supplier approval process. Suppliers are selected based on certain criteria $^{[17]}$. These criteria particularly for suppliers' selection may include:

(1) Company experience on the previous use of the 
suppliers.

(2) Ability to meet the organisation's requirements.

(3) Suppliers' experience with supplying the type of products/services.

(4) Suppliers' financial stability.

(5) Accredited certification of a Quality Management System (QMS).

(6) Price and delivery.

(7) Location.

Authorization on the supplier approval is managed via the system. The SAP based ERP system has the user authorization, which warrants only the users who have the right to perform a specific action or retrieve a certain section of information. The purchasing process will be managed by the purchasing manager irrespective of the person who is filling the role. For purchasing, the BS/EN9100 clause 7.4.1e also addresses the person approved to add new suppliers on the supplier approved register on the system. In this case, having the restricted access for adding new supplier ensures the requirements of the standard being met and the approval process being correctly followed ${ }^{[16]}$.

The supplier's categories enable the user to identify suppliers' scope of approval. Product and none product related suppliers need to be identified so as to avoid monitoring suppliers having little impact on the supply chain. The SAP based ERP system records every transaction carried out, whether they are domestic suppliers or the product related suppliers.

Communicating requirements to suppliers is a crucial step in the purchasing process. To address this part of the requirement, a supplier quality assurance requirements document was created. This document includes seven specific areas listed by the standard as well as the additional organization specific requirements. These requirements range from flowing down engineering requirements and clarifying any ambiguity of the requirement to record retention period, etc. The clause in the standard referring to these particular requirements is BS/EN9100 clause 7.4.2 ${ }^{[16]}$.

\subsection{In-process suppliers management and decision makings}

The BS/EN9100 clause 7.4.1f is related to risks and describes the organization to determine and manage risks in selecting a supplier ${ }^{[16]}$. Risks associated with supply chain can vary depending on the nature of the product or service and the geographical location. The risks of a supplier can also be determined by the history of using the supplier as well as the associated technical capability to meet the requirements of the customer.

Establishing an automated supplier delivery performance KPI enables the organization to monitor suppliers continuously and make decisions based on factual data. Actions taken are based on the performance of suppliers in providing each of the key material and outsourced process to the product related. Some of these actions were taken to disapprove and make inactive the suppliers who were not meeting the quality and delivery requirements consistently. BS/EN9100 clause 7.4.1c clearly states that actions need to be taken based on the performance of the supplier ${ }^{[16]}$.

\subsection{Implementation perspectives of using the SAP based system}

The implementation of a SAP based ERP system can be very costly exercise for manufacturing SMEs. This is due to the nature of the software functions and the configuration process to make tailored to meet the needs of different business organizations. Understanding the benefits of the SAP based ERP system is important especially in justifying the investment to implement the software tool at an engineering enterprise. SAP based ERP system can provide up-to-the-minute visibility of KPIs across every facet of business operations, including real-time monitoring, root cause analysis, risk mitigation, predictive modeling, and optimization, etc, so as to help the company run a more intelligent aerospace manufacturing business in a very competitive manner. Some of the other benefits that can be achieved by ERP adopters are improved coordination between departments and improved internal communication $^{[18]}$. The data and information gathered allow manufacturers to understand their current situation and to learn more about their workforce. This information is essential in improving efficiency and productivity ${ }^{[19]}$.

The supplier management and purchasing process performance is monitored and controlled by using the SAP-based system as illustrated in Fig. 5, which also demonstrates the different interactions between the various aspects of the ERP system and where the input data coming from. The configuration of the ERP system was undertaken to ensure the various activities carried out being in compliance with the aerospace quality management system. For example, any disapproved supplier will be inactive on the system through the in-process monitoring in light of the quality assurance clauses embedded. This will stop any purchase order raised against a supplier who has been disapproved.

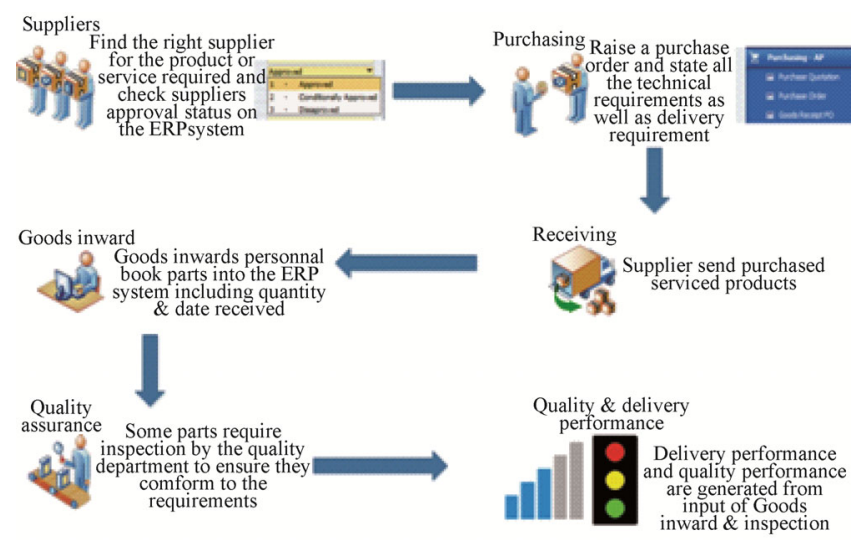

Fig. 5. Purchasing/supplier performance monitoring by using the SAP-based system 
SAP based ERP modules have different functions related to different aspects of the business. The modules include: Sales, Production, Human resources, Process planning, and financial accounting, etc. Some of the modules in SAP based system also provide the aid in meeting requirements other than supply chain management requirement of the BS/EN 9100. The process planning and production support modules are essential for supporting to maintain the traceability throughout the manufacturing process. The aerospace manufacturing standards impose a lot of emphasis on product-related manufacturing traceability. In a computer integrated manufacturing environment, various computerised tools, such as ERP systems and other pieces of equipment, are used to support the overall manufacturing plan $^{[20]}$

\section{Conclusions}

Implementation of the BS/EN 9100 Aerospace and Defense Quality standard creates opportunities for precision manufacturing SMEs to enter the aerospace manufacturing supply chain, albeit it is also essentially required. Supply chain management is considered to be one of the most crucial processes in precision manufacturing organizations. A good base of suppliers and effective supply chain management are often reflected and also indispensable in the production of high quality products at low cost in the shortest delivery time. This paper presents an industrial feasible approach for supply chain quality management and assurance by integrating SAP based system with implementation of BS/EN 9100 Aerospace and Defense Quality standards. The requirements of the Quality Standard related to supplier management are built into the SAP based system by reconfiguring the system and integrating it with the BS/EN 9100 quality control and assurance clauses and algorithms developed. This makes it easier to meet the requirements of the quality standard at manufacturing SMEs where resources are constrained. The system can also be used as an enabling tool for the company management team to handle real time data and make agile and responsive decision makings in a quantitative analysis based manner.

\section{Acknowledgements}

The authors would like to thank the technical and financial support for this research (R85169) from Mollart Engineering Ltd.

\section{References}

[1] BARTON R, THOMAS A. Implementation of intelligent systems, enabling integration of SMEs to high-value supply chain networks[J]. Engineering Applications of Artificial Intelligence, 2009, 22(6): 929-938.

[2] CHIN T A, HAMID A B A, RASLI A, et al. Adoption of supply chain management in SMEs[J]. Procedia - Social and Behavioral Sciences, 2012, 65: 614-619.
[3] RODRÍGUEZ-ENRÍQUEZ C A, ALOR-HERNÁNDEZ G, MEJIA-MIRANDA J, et al. Supply chain knowledge management supported by a simple knowledge organization system[J]. Electronic Commerce Research and Applications, 2016, 19: 1-18.

[4] PAIK S. Supply management in small and medium-sized enterprises: role of SME size[J]. Supply Chain Forum: An International Journal, Taylor \& Francis, 2011: 10-21.

[5] SMITH D J, TRANFIELD D. Talented suppliers? Strategic change and innovation in the $\mathrm{UK}$ aerospace industry[J]. $R \& D$ Management, 2005, 35(1): 37-49.

[6] MOORE D M, Neal D J, ANTILL P D. Supply chain management in SMEs within the defense aerospace industry - A case of simplification or increased complexity?[J]. International Journal of Aerospace Management, 2001, 1(1): 35-45.

[7] TOMIĆ B, SPASOJEVIC-BRKIC V, KLARIN M. Quality management system for the aerospace industry[J]. Journal of Engineering Management and Competitiveness, 2012, 2(1): 11-15.

[8] HENDERSON J. Aerospace industry has potential for take-off[EB/OL]. (2016-02-25). http://search.proquest.com.ezproxy.brunel.ac.uk/docview/13984204 14 ?pq-origsite $=$ summon.

[9] GORDON D K. Supply chain management remains aerospace challenge[J]. Quality Progress, 2006, 39(7): 83-85.

[10] CHENG K, HARUN K. An integrated modelling method for assessment of quality systems applied to aerospace manufacturing supply chain[J]. Journal of Intelligent Manufacturing, 2012, 23: 1365-1378.

[11] British standards online (2011). BS EN 9101:2011Quality management systems. Audit requirements for aviation, space, and defence organizations[S/OL]. (2016-02-11). https://bsol.bsigroup.com/Bibliographic/BibliographicInfoData/000 000000030195807.

[12] CHENG K, BATEMAN R J. e-Manufacturing: characteristics, applications and potentials[J]. Progress in Natural Science, 2008, 18: 1323-1328.

[13] KAGERMANN Henning, JOHANNES Helbig, ARIANE Hellinger, et al. Recommendations for implementing the strategic initiative INDUSTRIE 4.0: Securing the future of German manufacturing industry $[\mathrm{R}]$. Final report of the Industrie 4.0 Working Group, Forschungsunion, 2013.

[14] CHENG K, PAN P Y, HARRISON, D K. Web-based design and manufacturing support systems: implementation perspectives[J]. International Journal of Computer Integrated Manufacturing, 2001, 14(1): 14-27.

[15] JOVANE F, YOSHIKAWA H, ALTING L, et al. The incoming global technological and industrial revolution towards competitive sustainable manufacturing[J]. CIRP Annals-Manufacturing Technology, 2008, 57(2): 641-659.

[16] British standards online (2009) BS EN 9100:2009 Quality management systems.Requirements for Aviation, Space and Defense Organizations [S/OL].

(2016-02-11) https://bsol-bsigroup-com.ezproxy.brunel.ac.uk/Bibliographic/Bibli ographicInfoData/000000000030318464

[17] BAG S. World class procurement practices and its impact on firm performance: A selected case study of an Indian manufacturing firm[J]. Journal of Supply Chain Management Systems, 2012, 1(3): 27-39.

[18] SPATHIS C, CONSTANDTINIDES S. The usefulness of ERP systems for effective management[J]. Industrial Management \& Data Systems, 2003, 103(9): 677-684.

[19] KATCHASUWANMANEE K, BATEMAN R, CHENG K. Development of the energy-smart production management system (e-ProMan): a big data driven approach, analysis and optimization[J]. Proceedings of the IMechE, Part B: Journal of Engineering Manufacture, 2016, 230(5): 972-978.

[20] HUANG C Y, CHENG K, HOLT A. An integrated manufacturing 
network management framework by using mobile agent[J]. International Journal of Advanced Manufacturing Technology, 2007, 32(7-8): 822-833.

\section{Biographical notes}

HUSSEIN Abdullahi, born in June 1989, is currently a $\mathrm{PhD}$ candidate in Manufacturing \& Enterprise Engineering Research, Brunel University London, United Kingdom. He received his master degree on Engineering Management from Brunel University London, United Kingdom, in 2013. He received his bachelor degree from Northampton University, United Kingdom, in 2012. His current research interests include aerospace quality management system, advanced manufacturing systems, supply chain management and precision engineering SMEs.

Tel: +44(0)7878281448;

E-mail: abdullahi-hussein1@hotmail.co.uk; abdullahi.hussein@brunel.ac.uk

CHENG Kai, born in December 1961, is currently a Chair Professor at College of Engineering, Design and Physical Sciences, Brunel University London, United Kingdom. He received his $\mathrm{PhD}$ in 1994 from Liverpool John Moores University, United Kingdom. His current research interests include precision and micro manufacturing, design of high precision machine tools, Sustainable manufacturing systems and e-manufacturing. Tel: +44 (0)1895 267255; E-mail: kai.cheng@brunel.ac.uk 